\title{
構造的不確かさを含む線形離散時間システムに対する 過渡応答を考慮したロバスト制御*
}

\author{
大 屋 英 稔*1, 萩 野 剛二郎*2 \\ Robust Control Giving Consideration to Transient Behavior \\ for Linear Discrete-Time Systems with Structured Uncertainties
}

\author{
Hidetoshi OYA*3 and Kojiro HAGINO \\ ${ }^{* 3}$ Department of Systems Engineering, The University of Electro-Communications, \\ 1-5-1 Chofugaoka, Chofu-shi, Tokyo, 182-8585 Japan
}

\begin{abstract}
In this paper, we present a robust controller design method which achieves performance robustness together with robust stability for linear discrete-time systems with structured uncertainties. The performance robustness means that comparing the transient behavior of the uncertain system with a desired one generated by the nominal system, the deterioration of control performance is suppressed and at the same time excessive control input is avoided. In this approach, the control law consists of a state feedback with a feedback gain designed by using the nominal system and a compensation input for the purpose of reducing the error between the real transient behavior and the desired one. The compensation input is determined so that an upper bound on a quadratic cost function is minimized directly without trial and error. We show that a condition for the existence of the compensation input minimizing the upper bound on the quadratic cost function is given in terms of linear matrix inequalities (LMIs). Finally, numerical examples are presented.
\end{abstract}

Key Words: Error System, Compensation Input, Direct Minimization of the Upper Bound on the Quadratic Cost Function, Keeping Desired Transient Performance

\section{1. ま え が き}

近年, 不確かさを含む線形多入出カシステムに対し, 2 次コスト制御 ${ }^{(1)(2)}$ やロバスト $H_{2}$ 制御 $^{(3)(4)}$ など, 達成 可能なパフォーマンスとの関係を明確にした形でのコ ントローラ設計法ついて盛んに研究がなされてきた. また, 過渡応答特性の改善のために, 安定性の確保に 加え, 閉ループ極に関する付加的な制約を満たすコン トローラ設計法についてもいくつか提案されている (5)(6). しかしながら，一般の線形多入出力システムに 対して, 望ましい過渡応答特性を得るために, 閉ルー プ極の存在領域をどのように選定すればよいかは明 らかにされていない.さらに,これらの制御方式は最 悪ケースに対して設計された単一の固定ゲインコント ローラを用いているため, 不確かさの摂動領域が実際 の提動幅より大きく見積もられた場合には保守的な結 果となってしまうといった問題点がある.

この問題に対し，筆者らは線形不確定連続時間シス テムに対するレギュレータ問題において, ノミナルシ ステムを利用して生成した制御対象の望ましい軌道と

* 原稿受付 2003 年 4 月 9 日.

*1 正員, 電気通信大学システム工学科( 182-8585 調布市調 布ヶ丘 1-5-1).

*2 電気通信大学システム工学科.

E-mail : hide-o@se.uec.ac.jp
実際の応答を直接比較することにより，不確かさによ る応答特性の劣化を抑制するコントローラ設計法を標 準的な線形二次制御問題の拡張型として提案した (7). 文献 ${ }^{(7)}$ では不確かさの影響を補正するという観点から, 制御則を状態フィードバック則と補償入力からなるも のとし，補償入力を誤差システム (望ましい軌道と実 際の応答とのずれ)に対する 2 次形式評価関数の上界 値を最小化するように決定した．また，補傥入力が存 在するための十分条件がリカッチ方程式の可解性に帰 着されることを示し, 設計パラメータを設定する指針 を与えた. 文献 ${ }^{(7)} の$ 制御方式は, 不確かさに関する才 ンライン情報として, 望ましい軌道と実際の応答との 誤差情報をコントローラに反映させることにより, 従 来の固定ゲインによるロバスト制御方式に比べ, 構造 は複雑になるものの, より柔軟で適応的な制御系を構 成することができる. しかしながら，文献(7)では設計 パラメータをリカッチ方程式の正定対称解が存在する 範囲で試行錯誤的に設定するため, 2 次形式評価関数 の上界値の厳密な意味での最小化とはなっていない.

そこで, 本論文では文献 ${ }^{(7)}$ の結果を線形離散時間シ ステムに拡張し, 2 次形式評価関数の上界値を直接最 小化することにより, 試行錯誤的な手続きを踏むこと 
なく，補鰂入力を設計することを考える．具体的には， 構造的不確かさのもとで, 補償入力を制御対象とノミ ナルシステムからなる誤差システムに対する 2 次形式 評価関数の上界值を直接最小化するように決定する.

本論文では, 2 次形式評価関数の上界値を直接最小 化する補償入力が存在するための十分条件が線形行 列不等式 (LMI) で記述されることを示し, 数值例に より本制御手法の有効性を検証する. なお, 本論文 で用いる記法は次の通りである. $A^{T}$ は行列 $A$ の転 置を表し, $\operatorname{Tr}\{A\}$ は行列 $A$ のトレースを表す. また, $\operatorname{diag}\left(A_{1}, \cdots, A_{n}\right)$ は行列 $A_{i}(i=1, \cdots, n)$ を要素にもつ ブロック対角行列, $I_{n}$ は $n$ 次の単位行列を表す.さ らに, $E\{\cdot\}$ は期待値を示す.

\section{2. 問題の記 述}

次式の線形不確定離散時間システムを考える.

$$
x(k+1)=A(\theta) x(k)+B(\theta) u(k)
$$

$x(k) \in \Re^{n}, u(k) \in \Re^{m}$ は，それぞれ制御対象における 状態, 制御入力ベクトルであり, 状態 $x(k)$ は完全に観 測できるものとする. また, $A(\theta), B(\theta)$ はそれぞれ適 当なサイズとし, $\theta(k) \in \mathfrak{R}^{N}$ を末知パラメータとして 次式のように記述されるものとする.

$$
\left.\begin{array}{l}
A(\theta)=A+\sum_{i=1}^{N} \theta_{i}(k) A_{i} \\
B(\theta)=B+\sum_{i=1}^{N} \theta_{i}(k) B_{i}
\end{array}\right\}
$$

式 (2)における $A, B$ はノミナル值を表す定数行列であ り, $A_{i}, B_{i}$ は未知パラメータの構造を表す定数行列で ある. また, 未知パラメータ $\theta \in \Re^{N}$ は次式で記述さ れる $N$ 次元棈円体領域に属するものとし, $\forall \theta \in \Delta に$ 関して $(A(\theta), B(\theta))$ は可制御ペアであるとする.

$$
\left.\begin{array}{l}
\Delta \triangleq\left\{\theta \in \Re^{N} \mid \theta^{T}(k) \Sigma^{-1} \theta(k) \leq 1\right\} \\
\Sigma=\operatorname{diag}\left(\sigma_{1}^{2}, \cdots, \sigma_{N}^{2}\right)
\end{array}\right\}
$$

式(1)において, 未知パラメータ $\boldsymbol{\theta} \in \Re^{N}$ を無視した ノミナルシステムは次式で記述されるものとする.

$$
\bar{x}(k+1)=A \bar{x}(k)+B \bar{u}(k)
$$

$\bar{x}(k) \in \Re^{n}, \bar{u}(k) \in \Re^{m}$ はそれぞれノミナルシステムに おける状態, 制御入力ベクトルである.

本論文では, システマティックに制御対象の望まし い時間応答を生成するために, ノミナルシステムに対 する線形 2 次制御問題を採用する (もちろん, 極配置 法など, 他の設計手法を用いることも可能である $)^{(7)}$. よく知られているように, 最適制御入力 $\bar{u}(k)$ は

$$
\bar{u}(k)=-K \bar{x}(k)
$$

と与えられる. 式 (5) のフィードバックゲイン行列 $K$ は次式のリカッチ方程式の正定対称解 $P$ を用いて $K=\left(R+B^{T} P B\right)^{-1} B^{T} P A$ と求められる.

$$
P=A^{T} P A-A^{T} P B\left(R+B^{T} P B\right)^{-1} B^{T} P A+Q
$$

また, 式(6)の $Q \in \Re^{n \times n}, R \in \Re^{m \times m}$ はそれぞれ準正定 値, 正定值の重み行列であり, 所望の応答特性を実現 するようにあらかじめ設定しておく. ただし, 重み行 列 $Q$ は $(H, A)$ が可観測ペアとなる行列 $H \in \Re^{r \times n}$ を用 いて $Q=H^{T} H$ と表されるものとする. このとき, 式 (5) の制御入力 $\bar{u}(k)$ を用いることによって得られるノ ミナルシステムの閉ループ系は漸近安定となる ${ }^{(8)}$.

式 (1) の制御対象に対して, 式 (5) のゲイン行列 $K$ を用いて次式の制御入力を施すことを考える(7).

$$
u(k) \triangleq-K x(k)+v(k)
$$

また, 未知パラメータの影響をオンライン情報として 利用するために, 制御対象の実際の応答と望ましい軌 道との誤差を $e(k) \triangleq x(k)-\bar{x}(k)$ と定義すると, 式 $(1)$, (4), (5), および(7)から誤差システムが

$$
e(k+1)=\bar{A}(\theta) e(k)+B(\theta) v(k)+\bar{A}_{e}(\theta) \bar{x}(k)
$$

と得られる. 式(8)において, $\bar{A}(\theta), \bar{A}_{e}(\theta)$ はそれぞれ $\bar{A}(\theta)=A(\theta)-B(\theta) K, \bar{A}_{e}(\theta)=\bar{A}(\theta)-(A-B K)$ を満た す行列である. さらに, 式 (8) の誤差システムに対し て次式の 2 次形式評価関数を設定する.

$$
J_{e}=\sum_{k=0}^{\infty}\left(e^{T}(k) Q_{e} e(k)+v^{T}(k) R_{e} v(k)\right)
$$

$Q_{e} \in \Re^{n \times n}, R_{e} \in \Re^{m \times m}$ は正定値の重み行列であり, 制 御対象の望ましい応答を得るように調整される.

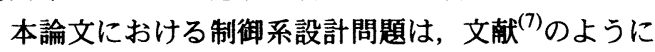
設計パラメータを試行錯誤的に設定することなく, 構 造的不確かさの存在のもとで, 式 (9) の 2 次形式評価 関数の上界值を直接最小化する補償入力を設計するこ とにより, 安定性の確保に加えて不確かさによる過渡 応答波形の劣化を㧕制することである.

\section{LMI による補俗入力の設計}

ここでは, 制御対象の構造的変動のもとで式 (9)の 2 次形式評価関数 $J_{e}$ の上界値を直接最小化する補償入 力 $v(k)$ が存在するための十分条件を導出する.

文献 ${ }^{(7)}$ と同様に補償入力 $v(k)$ を次式で定義する.

$$
v(k) \triangleq-F_{e} e(k)
$$

式 (10) の $F_{e}$ は補償ゲイン行列である. よって, 提案 するロバスト制御系の構成は図. 1のようになる. 


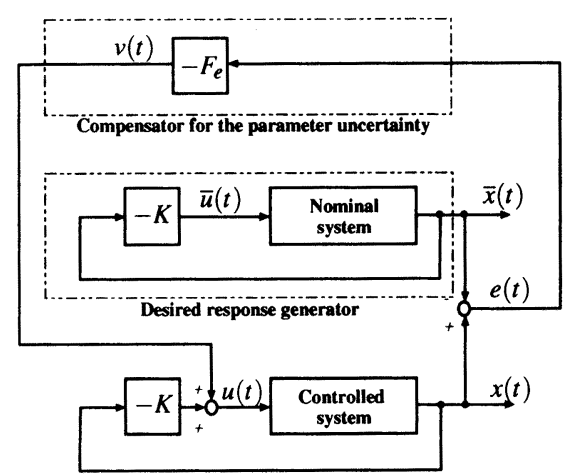

Fig. 1 Configuration of the proposed robust regulator

ここで, $v(k) \triangleq-F_{e} e(k)$ と任意の正定值行列 $X_{e} \in$ $\Re^{n \times n}$ ，および $P_{e} \in \Re^{n \times n}$ に関して成立する関係式

$$
\begin{aligned}
& \sum_{k=0}^{\infty}\left\{e^{T}(k+1) X_{e} e(k+1)-e^{T}(k) X_{e} e(k)\right. \\
& \left.+\bar{x}^{T}(k+1) P_{e} \bar{x}(k+1)-\bar{x}^{T}(k) P_{e} \bar{x}(k)\right\} \\
& -e(\infty) X_{e} e(\infty)-\bar{x}^{T}(\infty) P_{e} \bar{x}(\infty) \\
& +e^{T}(0) X_{e} e(0)+\bar{x}^{T}(0) P_{e} \bar{x}(0)=0
\end{aligned}
$$

を用いると式 (9) の 2 次形式評価関数は

$$
\begin{aligned}
J_{e}= & \sum_{k=0}^{\infty}\left[e ^ { T } ( k ) \left\{\left(\bar{A}(\theta)-B(\theta) F_{e}\right)^{T} X_{e}\right.\right. \\
& \left.\times\left(\bar{A}(\theta)-B(\theta) F_{e}\right)-X_{e}+Q_{e}+F_{e}^{T} R_{e} F_{e}\right\} e(k) \\
& +\bar{x}^{T}(k) \bar{A}_{e}^{T}(\theta) X_{e}\left(\bar{A}(\theta)-B(\theta) F_{e}\right) e(k) \\
& +e^{T}(k)\left(\bar{A}(\theta)-B(\theta) F_{e}\right)^{T} X_{e} \bar{A}_{e}(\theta) \bar{x}(k) \\
& \left.+\bar{x}^{T}(k)\left(\bar{A}^{T} P_{e} \bar{A}-P_{e}+\bar{A}_{e}^{T}(\theta) X_{e} \bar{A}_{e}(\theta)\right) \bar{x}(k)\right] \\
& -e^{T}(\infty) X_{e} e(\infty)-\bar{x}^{T}(\infty) P_{e} \bar{x}(\infty) \\
& +e^{T}(0) X_{e} e(0)+\bar{x}^{T}(0) P_{e} \bar{x}(0) \\
= & \sum_{k=0}^{\infty}\left(e^{T}(k) \bar{x}^{T}(k)\right) \Phi_{e}(\theta)\left(\begin{array}{l}
e(k) \\
\bar{x}(k)
\end{array}\right) \\
& -e^{T}(\infty) X_{e} e(\infty)-\bar{x}^{T}(\infty) P_{e} \bar{x}(\infty) \\
& +e^{T}(0) X_{e} e(0)+\bar{x}^{T}(0) P_{e} \bar{x}(0)
\end{aligned}
$$

と変形することができる. ここで, 式(4), (5), および (8) の関係式を用いた. また, 式 (12) において, $\bar{A}$ は $\bar{A}=A-B K$ なる漸近安定行列であり, $\Phi_{e}(\theta) \in \Re^{2 n \times 2 n}$ は次式で表される行列である.

$$
\begin{aligned}
& \Phi_{e}(\theta)=\left(\begin{array}{cc}
\Phi_{e_{11}}(\theta) & \Phi_{e_{12}}(\theta) \\
\Phi_{e_{12}}^{T}(\theta) & \bar{A}^{T} P_{e} \bar{A}-P_{e}+\bar{A}_{e}^{T}(\theta) X_{e} \bar{A}_{e}(\theta)
\end{array}\right) \\
& \Phi_{e_{11}}(\theta)=\left(\bar{A}(\theta)-B(\theta) F_{e}\right)^{T} X_{e}\left(\bar{A}(\theta)-B(\theta) F_{e}\right) \\
& -X_{e}+Q_{e}+F_{e}^{T} R_{e} F_{e} \\
& \Phi_{e_{12}}(\theta)=\left(\bar{A}(\theta)-B(\theta) F_{e}\right)^{T} X_{e} \bar{A}_{e}(\theta)
\end{aligned}
$$

ここで, 式 (8)の誤差システムの漸近安定性, 式 (1) の制御対象の潮近安定性, および式 (12)の 2 次形式 評価関数の上界值について, 次の補題を示しておく.

補題 3.1 式(13) の行列 $\Phi_{e}(\theta)$ に対して, 行列不等式

$$
\Phi_{e}(\theta) \leq 0 \quad \text { for } \quad \forall \theta \in \Delta
$$

を满足する補償ゲイン行列 $F_{e}$, および正定值行列 $X_{e}>0, P_{e}>0$ が存在するとき, 式 (8) の誤差システ 厶の渐近安定性, および式 ( 1 ) の制御対象の漸近安定 性が保証され, 式(12)の 2 次形式評価関数 $J_{e}$ の上界 值が次式のように与えられる.

$$
\begin{aligned}
J_{e} & \leq e^{T}(0) X_{e} e(0)+\bar{x}^{T}(0) P_{e} \bar{x}(0) \\
& \triangleq \mathscr{J}_{e} \quad \text { for } \quad \forall \theta \in \Delta
\end{aligned}
$$

証明 3.1 式(8) の誤差システム, および式 (4),(5) より 得られるノミナルシステムの閉ループ系からなる次式 の拡大システムを考える.

$$
\left(\begin{array}{l}
e(k) \\
\bar{x}(k)
\end{array}\right)=\mathscr{A}_{e}(\theta)\left(\begin{array}{l}
e(k) \\
\bar{x}(k)
\end{array}\right)
$$

ただし, $\mathscr{A}_{e}(\theta)$ は次式で表される行列である.

$$
\mathscr{A}_{e}(\theta)=\left(\begin{array}{cc}
A(\theta)-B(\theta) F_{e} & \bar{A}_{e}(\theta) \\
0 & \bar{A}
\end{array}\right)
$$

リヤプノフ関数の候補として, $e(k)$, および $\bar{x}(k)$ に 関する 2 次形式 $V(e, \bar{x}, k) \triangleq e^{T}(k) X_{e} e(k)+\bar{x}^{T}(k) P_{e} \bar{x}(k)$ を考え, 式 (16) の拡大システムの解軌道に沿って $\Delta V(e, \bar{x}, k) \triangleq V(e, \bar{x}, k+1)-V(e, \bar{x}, k)$ を計算すると, 次 式の関係式が得られる.

$$
\begin{aligned}
\Delta V(e, \bar{x}, k)= & e^{T}(k)\left\{\left(\bar{A}(\theta)-B(\theta) F_{e}\right)^{T} X_{e}\right. \\
& \left.\times\left(\bar{A}(\theta)-B(\theta) F_{e}\right)-X_{e}\right\} e(k) \\
& +\bar{x}^{T}(k) \bar{A}_{e}^{T}(\theta) X_{e}\left(\bar{A}(\theta)-B(\theta) F_{e}\right) e(k) \\
& +e^{T}(k)\left(\bar{A}(\theta)-B(\theta) F_{e}\right)^{T} X_{e} \bar{A}_{e}(\theta) \bar{x}(k) \\
& +\bar{x}^{T}(k)\left(\bar{A}^{T} P_{e} \bar{A}-P_{e}+\bar{A}_{e}^{T}(\theta) X_{e} \bar{A}_{e}(\theta)\right) \bar{x}(k) \\
= & \left(e^{T}(k) \bar{x}^{T}(k)\right) \Phi_{e}(\theta)\left(\begin{array}{c}
e(k) \\
\bar{x}(k)
\end{array}\right) \\
& -e^{T}(k)\left(Q_{e}+F_{e}^{T} R_{e} F_{e}\right) e(k)
\end{aligned}
$$

ここで, 行列不等式 $\Phi_{e}(\theta) \leq 0$ for $\forall \theta \in \Delta$ を満た す補償ゲイン行列 $F_{e}$, および正定值行列 $X_{e}, P_{e}$ が存在 すれば, 式(18)より, 2 次形式 $V_{e}(e, \bar{x}, k)$ について

$$
\Delta V(e, \bar{x}, k) \leq-e^{T}(k)\left(Q_{e}+F_{e}^{T} R_{e} F_{e}\right) e(k)
$$

なる関係式が成り立つ. 式(19)において, 重み行列 $Q_{e}, R_{e}$ は正定値行列であるので, 2 次形式 $V(e, \bar{x}, k)$ に 


$$
\begin{aligned}
\Psi_{e}(\theta) & =\left(\begin{array}{cc}
-S_{e} & 0 \\
0 & \bar{A}^{T} P_{e} \bar{A}-P_{e}
\end{array}\right)+\left(\begin{array}{ccc}
S_{e} & W_{e}^{T} & S_{e} \bar{A}^{T}(\theta)-W_{e}^{T} B^{T}(\theta) \\
0 & 0 & \bar{A}_{e}^{T}(\theta)
\end{array}\right)\left(\begin{array}{ccc}
Q_{e} & 0 & 0 \\
0 & R_{e} & 0 \\
0 & 0 & S_{e}^{-1}
\end{array}\right)\left(\begin{array}{cc}
S_{e} & 0 \\
W_{e} & 0 \\
\bar{A}(\theta) S_{e}-B(\theta) W_{e} & \bar{A}_{e}(\theta)
\end{array}\right) . \\
& \leq 0 \text { for } \forall \theta \in \Delta
\end{aligned}
$$

$$
\begin{aligned}
\Psi_{e}^{*}(\theta) & =\left(\begin{array}{ccccc}
-S_{e} & 0 & S_{e} & W_{e}^{T} & S_{e} \bar{A}^{T}(\theta)-W_{e}^{T} B^{T}(\theta) \\
0 & \bar{A}^{T} P_{e} \bar{A}-P_{e} & 0 & 0 & \bar{A}_{e}^{T}(\theta) \\
S_{e} & 0 & -Q_{e}^{-1} & 0 & 0 \\
W_{e} & 0 & 0 & -R_{e}^{-1} & 0 \\
\bar{A}(\theta) S_{e}-B(\theta) W_{e} & \bar{A}_{e}(\theta) & 0 & 0 & -S_{e}
\end{array}\right) \\
& \leq 0 \text { for } \forall \theta \in \Delta
\end{aligned}
$$

ついて次式の関係が成立する.

$$
\Delta V(e, \bar{x}, k)<0
$$

したがって, 式(14)の行列不等式を満たす補償ゲイ ン行列 $F_{e}$, および正定值行列 $X_{e}, P_{e}$ が存在すれば, 2 次形式 $V(e, \bar{x}, k)$ は式 (16) の拡大システムのリヤプノ フ関数となり, 式(16)の拡大システムの 2 次安定性 ${ }^{(9)}$ が保証される. このとき, $e(k) \rightarrow 0$ for $k \rightarrow \infty$ となり, 式 (8) の誤差システムの漸近安定性が保証される.ま た, $\bar{x}(k) \rightarrow 0$ for $k \rightarrow \infty$, および $e(k) \triangleq x(k)-\bar{x}(k)$ の関倸を考慮すれば, $x(k) \rightarrow 0$ for $k \rightarrow \infty$ となり, 式 (1)の制御対象の漸近安定性も保証される.

さらに, 式 (19) の両辺について, 0 からゅまでの 和をとると次式が得られる.

$$
\begin{aligned}
& e^{T}(\infty) X_{e} e(\infty)+\bar{x}^{T}(\infty) P_{e} \bar{x}(\infty) \\
& -e^{T}(0) X_{e} e(0)-\bar{x}^{T}(0) P_{e} \bar{x}(0) \\
& \leq-\sum_{k=0}^{\infty} e^{T}(k)\left(Q_{e}+F_{e}^{T} R_{e} F_{e}\right) e(k) \\
& =-J_{e}
\end{aligned}
$$

ここで, 式(16) の拡大システムが 2 次安定, すなわち $e(\infty)=\bar{x}(\infty)=0$ であることより, 式 $(21)$ は

$$
\begin{aligned}
J_{e} & =\sum_{k=0}^{\infty} e^{T}(k)\left(Q_{e}+F_{e}^{T} R_{e} F_{e}\right) e(k) \\
& \leq e^{T}(0) X_{e} e(0)+\bar{x}^{T}(0) P_{e} \bar{x}(0) \\
& =\mathscr{J}_{e}
\end{aligned}
$$

と等価である. したがって, 2 次形式評価関数の上界値 は式(15)で与えられる.

式 (15) の 2 次形式評価関数の上界值は初期誤差 $e(0)$, およびノミナルシステムの初期値 $\bar{x}(0)$ に依存した形と なっている. 本論文では, これらの初期值に依存しない
形で補償入力 $v(k)$ を設計するために $X_{e}^{*} \triangleq \operatorname{diag}\left(X_{e}, P_{e}\right)$ なる行列を導入し, $e(0)$ と $\bar{x}(0)$ について, $E\{e(0)\}=$ $E\{\bar{x}(0)\}=0$, および $E\left\{e(0) e^{T}(0)\right\}=E\left\{\bar{x}(0) \bar{x}^{T}(0)\right\}=$ $I_{n}$ を仮定して得られる平均の意味での 2 次形式評価関 数の上界値 $E\left\{\mathscr{J}_{e}\right\}=\operatorname{Tr}\left\{X_{e}^{*}\right\}$ を最小化する問題を考 える(1)(10). すなわち, 次式の制約付き最適化問題を解 くことを考える.

$$
\begin{aligned}
& \operatorname{Min}_{e}, F_{e}, P_{e}\left.\operatorname{Tr}\left\{X_{e}^{*}\right\}\right] \text { subject to } \\
& \text { eq.(14), } X_{e}>0 \text { and } P_{e}>0
\end{aligned}
$$

ここで, $S_{e} \triangleq X_{e}^{-1}, W_{e} \triangleq F_{e} S_{e}{ }^{(10)}$ なる行列を導入して, 式 (14) の条件式 $\Phi_{e}(\theta) \leq 0$ for $\forall \theta \in \Delta$ の両側から $\operatorname{diag}\left(S_{e}, I_{n}\right)$ をかけて整理すれば, 式 (24) が得られる. ここで, $\Psi_{e}(\theta) \triangleq \operatorname{diag}\left(S_{e}, I_{n}\right) \Phi_{e}(\theta) \operatorname{diag}\left(S_{e}, I_{n}\right)$ である. さらに Schur complement を用いると, 式(24)の行列不 等式は式(25)のように変形することができる. 式(25) は, $S_{e}, W_{e}$, および $P_{e}$ に関する線形行列不等式 $(\mathrm{LMI})$ で あるから, 式 (3) で表される $N$ 次元棈円体領域 $\Delta$ を覆 う最小の超直方体領域 $\bar{\Delta} \triangleq\left\{\theta \in \Re^{N}|| \theta_{i}(k) \mid \leq \sigma_{i}\right\}$ の $2^{N}$ 個の端点集合

$$
\Delta_{v e x} \triangleq\left\{\theta \in \Re^{N} \mid \theta_{i}=\sigma_{i} \text { or } \theta_{i}=-\sigma_{i}\right\}
$$

を考えると, $\forall \theta \in \Delta$ に関して式 (25) の行列不等式が 成り立つことは, 次式の行列不等式が成立することと 等価である.

$$
\Psi_{e}^{*}(\theta) \leq 0 \text { for } \forall \theta \in \Delta_{\text {vex }}
$$

さらに, $S_{e} \triangleq X_{e}^{-1}$ の関係を考虑しつつ, $\operatorname{Tr}\left\{X_{e}^{*}\right\}$ の最 小化を図るために

$$
\begin{aligned}
& Z_{e} \geq X_{e}>0 \Longleftrightarrow\left(\begin{array}{ll}
Z_{e} & I_{n} \\
I_{n} & S_{e}
\end{array}\right) \geq 0 \\
& Z_{e}^{*} \triangleq \operatorname{diag}\left(Z_{e}, P_{e}\right)
\end{aligned}
$$


を满たす 2 つの補助変数 $Z_{e} \in \Re^{n \times n}$, および $Z_{e}^{*} \in$ $\Re^{2 n \times 2 n}$ を導入することにより, $\operatorname{Tr}\left\{X_{e}^{*}\right\}$ を最小化す るかわりに $\operatorname{Tr}\left\{Z_{e}^{*}\right\}$ を最小化することを考える.

したがって, 式 (23)の制約付き最適化問題は, 次式 の制約付き凸最適化問題に帰着される.

$$
\begin{aligned}
& \underset{Z_{e}, S_{e}, W_{e}, P_{e}}{\operatorname{Min}}\left[\operatorname{Tr}\left\{Z_{e}^{*}\right\}\right] \text { subject to } \\
& \text { eqs.(27) and (28), } S_{e}>0 \text { and } P_{e}>0
\end{aligned}
$$

式 (30) の制約付き凸最適化問題の最適解 $Z_{e}>0, S_{e}>$ $0, W_{e}$, および $P_{e}>0$ が存在すれば, 補償入力 $v(k)$ は 次式のように求められる.

$$
\begin{aligned}
& v(k) \triangleq-F_{e} e(k) \\
& F_{e}=W_{e} S_{e}^{-1}
\end{aligned}
$$

なお, 補償入力 $v(k)$ を得るために解く必要のある 式 (30) の制約つき凸最適化問題は MATLAB の LMI Control Toolbox や Scilab の LMITOOL など, 種々の LMI 求解ツールを用いて容易に解くことができる.

以上を定理にまとめると次のようになる.

定理 3.1 式 (12) の 2 次形式評価関数 $J_{e}$ の上界值を直 接最小化する補償入力 $v(k)$ が存在するための十分条件 は, 次式の制約付き凸最適化問題の最適解 $Z_{e}>0, S_{e}>$ $0, W_{e}$, および $P_{e}>0$ が存在することである.

$$
\begin{aligned}
& \underset{Z_{e}, S_{e}, W_{e}, P_{e}}{\operatorname{Min}}\left[\operatorname{Tr}\left\{Z_{e}^{*}\right\}\right] \text { subject to } \\
& \text { eqs.(27) and (28), } S_{e}>0 \text { and } P_{e}>0
\end{aligned}
$$

ただし, $Z_{e}^{*}$ は $Z_{e}^{*} \triangleq \operatorname{diag}\left(Z_{e}, P_{e}\right)$ を満たす行列である.

制約付き凸最適化問題の最適解 $Z_{e}>0, S_{e}>0, W_{e}$, および $P_{e}>0$ が存在すれば, 補償入力 $v(k)$ は次式の ように求められる.

$$
\begin{aligned}
& v(k) \triangleq-F_{e} e(k) \\
& F_{e}=W_{e} S_{e}^{-1}
\end{aligned}
$$

注意 3.1 本論文では, 確定系に対する状態フィード バック系を考えているため, 制御対象の初期状態 $x(0)$ を用いてノミナルシステムの初期値 $\bar{x}(0)$ を設定する, すなわち $\bar{x}(0)=x(0)$ とすることができる. このとき, 初期誤差は $e(0)=0$ となり, 2 次形式評価関数の上界 值は, 式(15)より, 次式のようになる.

$$
\mathscr{J}_{e}=\bar{x}^{T}(0) P_{e} \bar{x}(0)
$$

さらに,この場合, 未知パラメータが実際には存在し ない, すなわち $\theta=0$ であれば, 制御対象の応答がノ ミナルシステムを利用して生成した望ましい軌道と一
致するだけでなく, 制御入カもノミナルシステムにお ける制御入力と一致する(7).

また，特別な場合ではあるが，ノミナルシステムの 初期値を $\bar{x}(0)=0$ と設定とした場合, $e(k)=x(k)$ とな ることから, 式 (9) の 2 次形式評価関数は

$$
J_{e}=\sum_{k=0}^{\infty}\left(x^{T}(k) Q_{e} x(k)+v^{T}(k) R_{e} v(k)\right)
$$

と表され, 式 (10) より, 補供入力 $v(k)$ も $v(k)=$ $-F_{e} x(k)$ となる. さらに, 2 次形式評価関数の上界値 は, 式(15)より次式のようになり，2 次コスト保証制 御に対応していることがわかる.

$$
\mathscr{J}_{e}=x^{T}(0) X_{e} x(0)
$$

ただし，本制御方式と通常の 2 次コスト保証制御では, 解くべき最適化問題が異なるので，ノミナルシステム の初期值を $\bar{x}(0)=0$ と設定としたからといって, 両者 が一致するわけではないことに注意する。

\section{4. 数 值 例}

ここでは, 簡単な数値例を通して, 本制御方式の有 効性を検証する. なお, 参考として, 文献 ${ }^{(1)}$ 基づい た 2 次コスト保証制御についても数值シミュレーショ ンを行った結果を示す．ただし，文献 ${ }^{(1)} に$ 基づいた 2 次コスト保証制御においても本論文と同様に線形行列 不等式 (LMI) を用いて設計した.

次式のように状態空間表現される線形不確定離散時 間システムを考える.

$$
\begin{aligned}
x(k+1)=\left(\begin{array}{cc}
0.75+\theta_{1}(k) & 1 \\
0 & 1
\end{array}\right) & x(k) \\
& +\left(\begin{array}{c}
0 \\
1+\theta_{2}(k)
\end{array}\right) u(k)
\end{aligned}
$$

ここで, 未知パラメータ $\theta_{1}(k), \theta_{2}(k)$ の摂動幅は，そ れぞれ $\theta_{1}(k) \in[-0.5,0.5], \theta_{2}(k) \in[-0.25,0.25]$ とあら かじめ見積もられているとする.

制御対象の望ましい軌道を生成するように式 (6) の重み行列 $Q, R$ を $Q=1.0 I_{2}, R=4.0$ と設定する と, 式 (5) のフィードバックゲイン行列 $K$ は $K=$ ( 0.12390 .7814 ) と得られた.

次に補停入力 $v(k)$ を設計するために式 (9) の 2 次 形式評価関数の重み行列 $Q_{e}, R_{e}$ をそれぞれ $Q_{e}=4.0 I_{2}$ and $R_{e}=1.0$ と設定し, 式 (30) の制約付き凸最適化問 題を解くと提案した制御則が次式のように求められた.

$$
\begin{aligned}
u(k)= & -\left(\begin{array}{ll}
0.1239 & 0.7814
\end{array}\right) x(k) \\
& -\left(\begin{array}{ll}
0.4704 & 1.0008
\end{array}\right) e(k)
\end{aligned}
$$




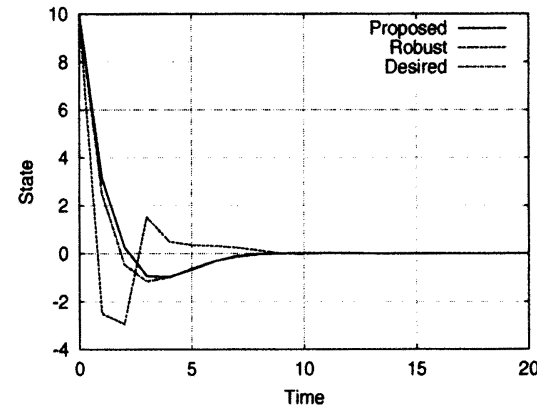

Fig. 2 Time response of $x_{1}(t)$ : Case 1

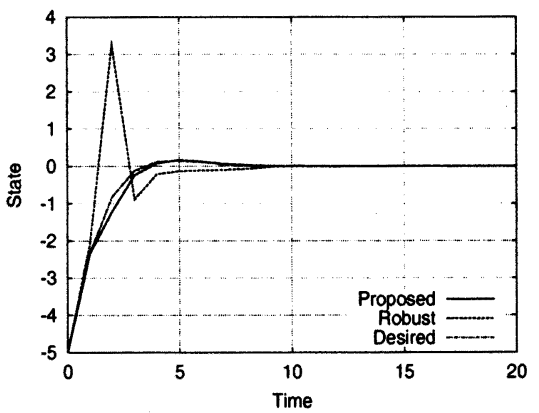

Fig. 3 Time response of $x_{2}(t):$ Case 1

一方，制御対象に対する 2 次形式評価関数の重み行 列 $Q_{r}, R_{r}$ をそれぞれ $Q_{r}=4.0 I_{2}, R_{r}=1.0$ と設定すると 文献 ${ }^{(1)}$ に基づいた 2 次コスト保証制御におけるフィー ドバックゲイン行列 $K_{r}$ は次式のように得られた.

$$
K_{r}=\left(\begin{array}{ll}
0.62051 .8274
\end{array}\right)
$$

ここでは, 未知パラメータ $\theta_{1}(k)$, および $\theta_{2}(k)$ の 変動パターンとして, 以下の 2 通りのパターンを考 える.

Case 1): $\theta_{1}(k)=-0.5 \cos (0.2 \pi t)$

$$
\theta_{2}(k)=0.25 \cos (0.2 \pi t)
$$

Case 2): $\theta_{1}(k)=-0.1, \theta_{2}(k)=0.05: 0 \leq t<5$

$$
\begin{aligned}
& \theta_{1}(k)=-0.1, \theta_{2}(k)=-0.05: 5 \leq t<10 \\
& \theta_{1}(k)=0.1, \theta_{2}(k)=0.05: 10 \leq t<15 \\
& \theta_{1}(k)=0.1, \theta_{2}(k)=-0.05: t \geq 15
\end{aligned}
$$

Case 1) は, 未知パラメータ $\theta_{1}(k), \theta_{2}(k)$ につ いて，あらかじめ見積もられた捸動幅 $\theta_{1}(k) \in$ $[-0.5,0.5], \theta_{2}(k) \in[-0.25,0.25]$ 内で滑らかに変動する 場合であり, Case 2) は, 未知パラメータ $\theta_{1}(k), \theta_{2}(k)$ の実際の摂動幅がそれぞれ $\theta_{1}(k) \in[-0.1,0.1], \theta_{2}(k) \in$ [-0.05,0.05] とあらかじめ見積もられた捸動幅の $20 \%$ であり, その区間内で大きく変動する場合である.

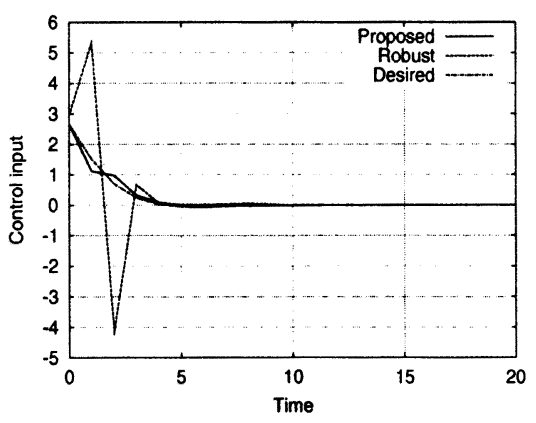

Fig. 4 Control inputs $u(t)$ : Case 1

図. 2〜7に各パターンのシミュレーション結果を示 す. 図中 Desired はそれぞれノミナルシステムを利用 して生成した制御対象の望ましい軌道，あるいは制御 入力を示しており, Robust は文献 ${ }^{(1)}$ 基づいた 2 次コ スト保証制御を適用した場合の時間応答，あるいは制 御入力を示している. ただし，ここでは制御対象の初 期状態を $x(0)=(10.0-5.0)^{T}$ とし，ノミナルシス テムの初期值を $\bar{x}(0)=(10.0-5.0)^{T}$, すなわち初期 誤差を $e(0)=\left(\begin{array}{ll}0.0 & 0.0\end{array}\right)^{T}$ とした.

Case 1), Case 2) のどちらの場合も Proposed によ る応答は，ノミナルシステムを利用して生成した望ま しい軌道に近い応答特性を示しており, 制御入力も著 しく大きくなっていない，特に，未知パラメータの摄 動幅が実際には小さい場合 (Case 2)) では，応答のみ ならず, 制御入力においても Desired とほほ一致した 軌道となっている.すなわち，ノミナルシステムに匹 敵する良好な制御性能が得られており，本制御則が実 際のパラメータ変動に関する情報 (制御対象の望まし い軌道と実際の応答との誤差情報) を反映した適応的 なものとなっていることがわかる.

この結果は, 実際のパラメータ変動の如何にかかわ らず,パラメータ変動の最悪值に対して設計された単 一の固定ゲインコントローラを用いる従来のロバスト 制御方式に比べ，実際のパラメータ変動に関する情報 をオンラインで利用することにより, 実際の未知パラ メータによる過渡応答波形の劣化を抑制することがで きるという点で, 構造は複雑になるものの, 提案した 制御方式がより柔軟で適応的な制御方式であることを 示している(7).

なお，ここでは図示していないが，本制御方式 (Proposed) において, ノミナルシステムの初期值を $\bar{x}(0)=0$ と設定した場合には, 文献 ${ }^{(1)}$ に基づいた 2 次 コスト保証制御 (Robust) とほほ同様な応答特性，制御 入力を示した. 


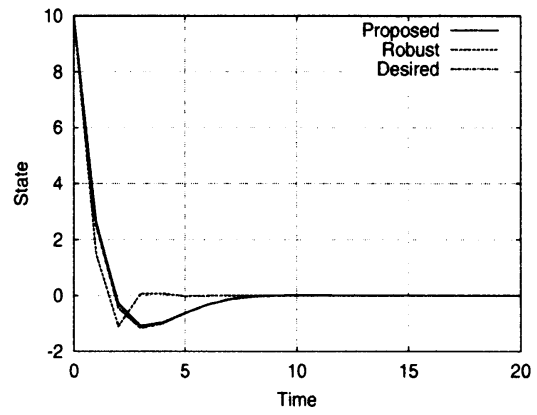

Fig. 5 Time response of $x_{1}(t):$ Case 2

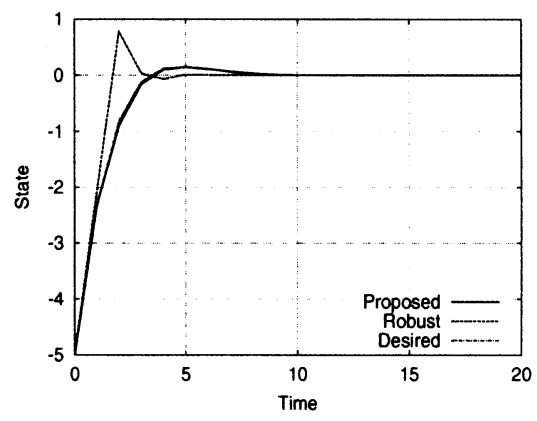

Fig. 6 Time response of $x_{2}(t):$ Case 2

\section{5.むすび}

本論文では, 文献 ${ }^{(7)}$ の結果を線形離散時間システム に拡張し, 文献 (7)のように試行錯誤的な手続きを踏む ことなく, 諤差システムに対する 2 次形式評価関数の 上界値を直接最小化することよる補償入力の設計法を 提案した. また，補偵入力が存在するための十分条件 が線形行列不等式 (LMI) で記述されることを示し, 数 值例により，本制御方式の有効性を検証した.

本制御方式は，不確かさに関するオンライン情報と して,ノミナルシステムを利用して生成した制御対象 の望ましい軌道と制御対象の実際の応答との誤差情 報をコントローラに反映させるという点で, 単一の固 定ゲインコントローラを用いる従来のロバスト制御 方式に比べ，より柔軟で適応的な制御系を構成するこ とができる. また, 制御則を得るために解く必要のあ る制約つき凸最適化問題も MATLAB の LMI Control Toolbox や Scilab の LMITOOL な゙, 種々の LMI 求 解ツールを用いることにより, 容易に解くことができ るという利点をもつ.

今後の課題としては, 制御対象の状態に直接アクセ ス出来ない場合に対するオブザーバ併合型ロバスト制 御や出カフィードバック系への拡張などが挙げられる.

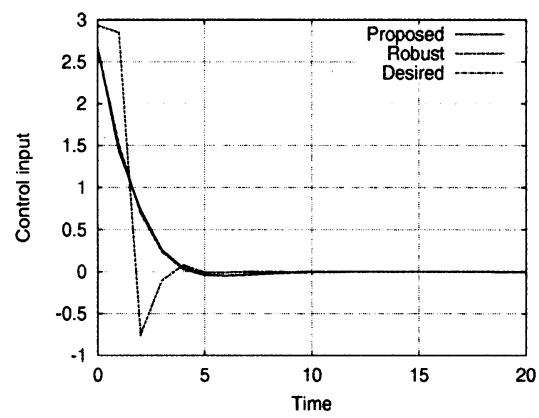

Fig. 7 Control inputs $u(t)$ : Case 2

\section{謝辞}

最後に, 有益な御意見, 御指摘を頂いた校閲担当委 員の方に感謝致します.

\section{文献}

(1) I. R. Petersen and D. C. McFarlane, "Optimal Guaranteed Cost Control and Filtering for Uncertain Linear Systems", IEEE Trans. Automat. Contr., Vol.39, No.9, pp.19711977, (1994)

(2) S. O. Reza Moheimani and I. R. Petersen, "Optimal Guaranteed Cost Control of Uncertain Systems via Static and Dynamic Output Feedback", Automatica, Vol.32, No.4, pp.575-579, (1996)

(3) A. A. Stoorvogel, "The Robust $\mathrm{H}_{2}$ Control Problem, A Worst-Case Design", IEEE Trans. Automat. Contr.,Vol.38, No.9, pp.1358-1370, (1993)

(4) 杉江 俊治, 手塚 知幸, “指定した $\mathrm{H}_{2}$ 制御性能を満たす ロバストレギュレーション”, 計測自動制御学会論文誌, Vol.29, No.7, pp.760-766, (1993)

(5) M. Chilali, P. Gahinet, " $H_{\infty}$ Design with Pole Placement Constraints, An LMI Approach", IEEE Trans. Automat. Contr., Vol.41, No.3, pp.358-367, (1996)

(6) M. Chilali, P. Gahinet and P. Apkarmann, "Robust Pole Placement in LMI Regions", IEEE Trans. Automat. Contr., Vol.44, No.12, pp.2257-2270, (1999)

(7) 大屋 英稔, 萩野 剛二郎, “不確かさを含む線形システ ムの時間応答を考虑したロバスト制御”, システム制御 情報学会論文誌, Vol.15, No.8, pp.404-412 (2002)

(8) B. D. O. Anderson and J. B. Moore, "Optimal Control : Linear Quadratic Methods”, Prentice-Hall, Inc., (1990)

(9) Y. $\mathrm{Li}$ and X. Xu, "The quadratic stability of a discretetime system with structured uncertainties", Int. J. Contr., Vol.72, No.16, pp.1427-1435, (1999)

(10) Oya H., and Hagino K., "Robust Servo System Design Giving Consideration to Transient Behavior for a Linear System with Structured Uncertainties", Proc. of the 27th Annual Conference of the IEEE Industrial Electronics Society, pp.692-697, Denvar, Colorado, USA, (2001)

(11) P. P. Khargonekar and M. A. Rotea, "Mixed $H_{2} / H_{\infty}$ Control , A Convex Optimization Approach", IEEE Trans. Automat. Contr., Vol.36, No.7, pp.824-837, (1991) 